\begin{tabular}{|c|c|c|}
\hline $\begin{array}{l}\text { PKS } \\
\text { PUBLIC } \\
\text { KNOOLEDGE } \\
\text { PROJECT }\end{array}$ & $\begin{array}{c}\text { Revista de GEOGRAFIA } \\
\text { (RECIFE) } \\
\text { http://www.revista.ufpe.br/revistageografia }\end{array}$ & $\begin{array}{l}\text { OJS } \\
\text { OPEN } \\
\text { JPURNAL } \\
\text { SYSTEMS }\end{array}$ \\
\hline
\end{tabular}

\title{
VIVER "ENTRE-LUGARES" E A TRANSTERRITORIALIDADE NO CAMPO DE REFUGIADOS DE DADAAB (QUÊNIA)
}

\begin{abstract}
Daniela Florêncio da Silva ${ }^{1}$
${ }^{1}$ Mestre em Geografia pela Universidade Federal de Pernambuco; Pesquisadora do Instituto de Estudos da Africa da UFPE. Email: danifs_br@yahoo.com.br

Artigo recebido em 15/08/2017 e aceito em 01/10/2017

RESUMO

Este artigo aborda a experiência de viver "entre-lugares" no campo de refugiados de Dadaab no nordeste do Quênia. Seus vinte e seis anos de existência são modelados por uma suspensão jurídica e por uma "prática" política de formação de campos de refugiados do governo queniano, impondo muitos limites no seu acolhimento. Esses limites impostos tornam o campo de refugiados de Dadaab um espaço de fronteira, onde além de contornados, esses limites são transpassados, mostrando que os conflitos ou estranhamentos vivenciados nesse espaço então delimitado, dinamizam o desenvolvimento de distintas realidades, agora entrelaçadas através do encontro das diferentes nacionalidades dos refugiados, de suas culturas e formas de ver o mundo. Sua descontinuidade espacial e de sentidos, tece uma geografia complexa, com outros ritmos.

Palavras-chave: Entre-lugares. Transterritorialidade. Campo de refugiados de Dadaab (Quênia)
\end{abstract}

\section{LIVE IN "IN-BETWEEN SPACES" AND THE TRANSTERRITORIALITY IN THE DADAAB REFUGEE CAMP (KENYA)}

\begin{abstract}
This article discusses the experience of living in "in-between spaces" in the Dadaab refugee camp in the northeast of Kenya. Its twenty-six years of existence are shaped by a juridical suspension and political "practice" of encampment by the kenyan government, imposing many limits on their reception. These imposed limits make Dadaab refugee camp a boundary space, where in addition to being circumvented, these limits are transpassed, showing that the conflicts or estrangements experienced in this space delimited, dynamize the development of different realities, now intertwined through the encounter of different nationalities of refugees, their cultures and ways of seeing the world. Its spatial and sense discontinuity, weaves a complex geography, with other rhythms. Keywords: In-between spaces. Transterritoriality. Dadaab refugee camp (Kenya)
\end{abstract}




\section{INTRODUÇ̃̃̃O}

A região nordeste do Quênia, na qual foi construído o campo de refugiados de Dadaab em 1991, parece estar vivenciando novas formas de viver entre fronteiras. Sua história é marcada por um entrecruzamento de somalis e quenianos, antes mesmo de suas definições coloniais. Nessa região de fronteira, ou até mesmo em Nairóbi, quenianos-somalis ou somalis-quenianos são difíceis de diferenciar, ${ }^{1}$ o próprio nome do pequeno vilarejo onde o campo foi instalado, Dadaab, é uma palavra somali, uma das principais línguas faladas nessa região queniana. Esse entrecruzamento formado por uma rede de comunidades nômades islâmicas, persiste, ultrapassando limites territoriais políticos cada vez mais desenvolvidos (WEITZBERG, 2017), como a cerca que está sendo construída entre o Quênia e a Somália. Hoje, esse campo de refugiados concentra grande parte desses encontros em suas cinco extensões (Hagadera, Dagahaley, Ifo, Ifo 2 e Kambioos), só que agora com um mosaico de 12 nacionalidades e 270 mil habitantes (UNHCR/KENYA, 2017), profundamente influenciado por sua maioria de $95 \%$ de refugiados da Somália.

Os passos deste artigo foram percorridos seguindo o caminho da pesquisa desenvolvida no mestrado sobre os fatores formadores do campo de refugiados de Dadaab e de sua dinâmica territorial. Nesse processo, o olhar das concepções teóricas pós-coloniais e as ambiguidades e ambivalências jurídicas e políticas de sua formação, expressas nas práticas biopolíticas e de exceção, delinearam as discussões. Sua formação marcada por geografias de exceção (MINCA, 2015) revela uma vida em suspensão, colocada "fora do ordenamento jurídico formal", onde os refugiados são "deslocados da relação entre nascimento e nacionalidade" e da cidadania (BRAGA, 2011, p. 15). Porém, esse espaço em suspensão jurídica e de espera desenvolve, também, outras percepções, como "um enclave de inesperados e metamorfoses" (CHAR, 1946 apud VIDAL, L.; MUSSET; VIDAL, D., 2011, p. 04). Os campos de refugiados, principalmente os que permanecem por muitos anos, apesar do controle, representam "uma situação de fronteira" e de liminaridade, compreendidos como "espaços da borda, do limite" ou do "entre dois" (AGIER, 2015, p. 282), onde a questão da alteridade, um dos fatores responsáveis por sua formação, tem nesse espaço de transição e de interação, um "repensar" e uma reconfiguração das formas de ver e conviver com os "outros" do mundo - suas culturas e identidades. Essa geografia de encontros do campo de refugiados

\footnotetext{
${ }^{1}$ Observação de Josephine Gitome, Professora e Diretora do Centre for Refugee Studies and Empowerment (KU-CRSE) da Kenyatta University de Nairóbi. Entrevista concedida no dia 04 de março de 2015, no centro de estudo citado. 
de Dadaab é percebida assim, através dos "entre-lugares" de Homi Bhabha (1998) e das transterritorialidades abordadas por Haesbaert (2014).

\section{O ESTAR “ENTRE-LUGARES" E A TRANSTERRITORIALIDADE NO CAMPO DE REFUGIADOS DE DADAAB}

A arte do presente de viver na fronteira, no final do século XX, e sua distinta face de transição, na qual o cruzamento entre o espaço e o tempo ou o movimento do mundo, produzem "figuras complexas de diferença e identidade, passado e presente, interior e exterior, inclusão e exclusão", revelam a existência de espaços intermediários de "movimento exploratório incessante" (BHABHA, 1998, p. 19). Nesses espaços, as identidades são construídas nas fronteiras de distintas realidades, sendo na contemporaneidade, cada vez mais "fragmentadas e fraturadas", assim como "multiplamente construídas ao longo de discursos, práticas e posições" que se cruzam ou entram em conflito, em constante processo de transformação (HALL, 2000, p. 108). Neste sentido, é importante vincular as discussões sobre identidade a todos os processos de transformações das populações e de suas culturas relativamente estáveis, como a globalização e o fenômeno global das migrações forçadas ou voluntárias (HALL, 2000). Observa-se, então, nessa complexa dinâmica territorial contemporânea, que as identidades a partir do pensamento de Stuart Hall podem ser também, "num sentido geográfico", definidas como "transterritoriais" (HAESBAERT, 2014, p. 273). As percepções identitárias contemporâneas, "antes restritas às lógicas binárias e fixas da modernidade", revelam identidades "cada vez mais fluídas e transitórias", influenciadas pelos processos migratórios e pela mobilidade humana (BARBOSA, 2012, p. 220).

Neste contexto, surge o "entre-lugar"2 de Homi Bhabha (1998). Espaço compreendido como uma fronteira ou "ponte" que reúne pessoas "enquanto passagem que atravessa" (HEIDEGGER, 1971 apud BHABHA, 1998, p. 29) durante o contato entre diferentes culturas, indo "além" de o simples estar ou passar ao lado, criando espaços de reorganização, de articulação e de entrelaçamento cultural e de identidade. Um lugar, assim, aberto às novas possibilidades. Essas reflexões do autor são feitas a partir das diferenças culturais expressas em uma literatura que não é homogênea ou tradicionalmente nacional, onde repercute a

\footnotetext{
${ }^{2}$ Essa foi a tradução usada para a expressão "in-between” utilizada por Bhabha. As tradutoras utilizaram como referência, o termo "entre-lugar" de Silviano Santiago, empregado em seu artigo O entre-lugar do discurso latino-americano de 1971. Homi Bhabha também o define como um "terceiro espaço", um "espaço intersticial" ou ainda, um estar no "além". 
possibilidade do reconhecimento dessas diferenças e a identificação de outras realidades. Essas diferenças ou "estranhamentos" presentes nessas obras literárias, permitem uma introdução extraterritorial e intercultural (BHABHA, 1998, p. 29). Para o autor:

viver no mundo estranho, encontrar suas ambivalências e ambiguidades encenadas na casa da ficção, ou encontrar sua separação e divisão representadas na obra de arte, é também afirmar um profundo desejo de solidariedade social: Estou buscando o encontro... (BHABHA, 1998, p. 42).

O estar "entre-lugares", então, significa a vivência de um espaço fronteiriço que vai além de uma delimitação territorial, abrangendo aspectos simbólicos e de significados culturais, construído a partir da diferença ou do encontro com o outro. Nesse encontro, o passado é retomado para ser renovado e reconfigurado em um "entre-lugar" "que inova" (BHABHA, 1998, p. 27).

O que é teoricamente inovador e politicamente crucial é a necessidade de passar além das narrativas de subjetividades originárias e iniciais e de focalizar aqueles momentos ou processos que são produzidos na articulação de diferenças culturais. Esses "entre-lugares" fornecem o terreno para a elaboração de estratégias de subjetivação - singular ou coletiva - que dão início a novos signos de identidade e postos inovadores de colaboração e contestação, no ato de definir a própria ideia de sociedade (BHABHA, 1998, p. 20, grifo do autor).

A importância dessas reflexões sobre os "entre-lugares" é percebida nas crises sociais contemporâneas desenvolvidas pela diferença cultural (BHABHA, 1998), principalmente nos últimos anos com o agravamento do terrorismo internacional e dos fluxos de refugiados no mundo e o embate dos países do hemisfério Norte para recebê-los. Em um território formado para a contenção de pessoas e para o controle de sua mobilidade, como o campo de refugiados de Dadaab, o estar "entre-lugares" assume um caráter compulsório, pela origem de sua formação. A proibição da mobilidade dos refugiados fora do espaço do campo, os obriga a vivenciar, por muitos anos ou décadas, um espaço de articulação de distintas culturas. As pesquisas sobre os aspectos biopolíticos e de convivência cultural em diferentes campos de refugiados no mundo, principalmente no continente africano e em Dadaab, do antropólogo Michel Agier destacam que aqueles que estão em um movimento errante, como os refugiados, acabam se adaptando e reorganizando o seu contexto social e de subjetividade, pois eles desenvolvem um tipo de pensamento em movimento, sempre projetando a possibilidade de 
avançar a cada passo ou atitude. Para o autor "o campo, sobretudo o que dura, representa uma situação de fronteira; é um espaço sempre sob controle, mas sempre liminar" (2015, p. 282).

Cada campo de refugiados tem o seu contexto de formação e se desenvolve de acordo com diferentes fatores, que vão desde as ações do Estado de acolhimento até o local em que foi instalado. Mas, mesmo diante de tantas distinções, seu território é marcado por diferentes intencionalidades e nacionalidades. As Nações Unidas, os países de acolhimento, as comunidades locais, os funcionários de organizações humanitárias e os refugiados juntos nesse território, refletem "geografias desiguais de poder e status", as quais moldam profundamente esse território, agora híbrido (GRBAC, 2013, p. 07, tradução nossa). A experiência de viver em um campo de refugiados desenvolve uma mudança cultural rápida devido ao contato de suas diferentes nacionalidades, motivado pelo deslocamento forçado e por sua instalação em um “dispositivo humanitário global-localizado" (AGIER, 2015, p. 128). Durante essa experiência eles aprendem outras línguas, principalmente o inglês básico, diferentes maneiras de moradia e de alimentação, apesar de existir uma preocupação com a preservação dos seus principais itens alimentares por parte das organizações internacionais de ajuda humanitária.

Em um campo de refugiados além da imensidão de espaço, como o de Dadaab e os seus $50 \mathrm{~km}^{2}$, existe uma imensidão de encontros entre diferentes povos, com suas faces e encantos, ao revelar diferentes geografias. Desses encontros entre refugiados, comunidade local, funcionários de organizações humanitárias internacionais, pesquisadores, jornalistas e todos que por lá passam, ao menos um olhar de alteridade é trocado. Por mais que se viva isolado ao tentar manter suas tradições, em represália ao que é novo e estranho, a situação do "campo" exige uma outra atitude. Nele, situações que não seriam vivenciadas no cotidiano normal dessas pessoas, têm no "campo" o seu embate, ou oportunidade. O campo de refugiados pode ser sim, um laboratório de práticas de controle, mas é também onde ocorre a formação de novas relações humanas e reflexões. É estar em um "jogo de múltiplas situações identitárias e múltiplas relações de poder" ou "estar entre ou um acionar/produzir" de “distintas territorialidades” (HAESBAERT, 2014, p. 100).

A conceituação dessa realidade é vista através da transterritorialidade abordada por Haesbaert, ou seja, "a ideia de trânsito entre territórios e o acionar simultâneo de múltiplas territorialidades", com ênfase no "estar entre", no "efetivamente híbrido" e no "atravessamento" (HAESBAERT, 2014, p. 284-285). A transterritorialidade vai "além" da multiterritorialidade, ela é o transpassar de territorialidades distintas ou o transpor de 
fronteiras. A descrição da transterritorialidade desenvolvida pelos autores Jones Goettert e Marcos Mondardo, revela esses aspectos vivenciados no contexto do campo de refugiados de Dadaab. Para os autores:

As transterritorialidades são disputas, tensões, conflitos, mediações e negociações entre territorialidades; a ideia se aproxima da de "transculturações", podendo ser aquelas a expressão territorial destas, configurando-se em uma espécie de "transmigração" cultural e de poder na relação entre territorialidades divergentes. Pessoas, grupos, classes e instituições transitam entre territorialidades como trânsito entre sentidos de viver, muitas vezes opostos e em contradição, ao mesmo tempo que transpassam e são transpassados por territorialidades, podendo, inclusive, potencializar e produzir entrecruzamentos e/ou superposições através da "mistura" (oriunda do próprio choque), com a produção de territorialidades cada vez mais híbridas. Esse trânsito é, quase sempre, carregado de disputas, tensões, conflitos, mediações e negociações, geralmente exacerbadas em situação ou condição de migração (GOETTERT; MONDARDO, 2009, p. 117, grifos dos autores).

No campo de refugiados de Dadaab a questão da etnia não é reforçada, e sim colocada em conflito, em um contexto de relativização e de construção de alternativas, assim como acontece com os refugiados que são instalados em centros urbanos (AGIER, 2002). Como exemplos, Michel Agier destaca a construção de uma igreja chamada United Church of Christ na extensão de Dagahaley, criada por refugiados sudaneses cristãos que reúne seguidores da igreja anglicana, da pentecostal, da ortodoxa e da African Inland Church e a ascensão social do clã somali bantu, minoria discriminada historicamente na Somália, mas no campo de refugiados de Dadaab tem tanto direito quanto os outros clãs da Somália. Outro aspecto importante é que as nacionalidades ganham maior importância no contexto do campo de refugiados de Dadaab que as diferenças étnicas existentes em seus países de origem. Em alguns casos, como ressalta Agier, na extensão Ifo, os refugiados etíopes de diferentes etnias, e até mesmo alguns eritreus, são todos identificados, simplesmente, por etíopes.

O caso Dadaab mostra que, neste domínio, o campo é um novo cenário sui generis e, até certo ponto, um quadro inovador, mesmo que as mudanças sociais e identitárias se baseiem no sofrimento coletivo e nos conflitos interpessoais, que de modo algum são específicos desse contexto. O campo engendra experiências de socialização híbrida que não são apenas multiétnicas, mas também plurais, nas quais estratégias de clãs atravessam estratégias étnicas e estas se sobrepõem às estratégias das organizações humanitárias da esfera "global” (AGIER, 2002, p. 336, grifo do autor, tradução nossa). 
Nos eventos organizados no campo, como os campeonatos de futebol ou de outros esportes, nas feiras de artesanato, no convívio em casas de chá, nas ruas dos comércios, nas Lan houses, nos salões de beleza, e principalmente nas escolas, ocorrem trocas culturais permeadas também por conflitos. Os refugiados somalis mais velhos, por exemplo, gostariam de fechar as "lojas de vídeo" e as "cafeterias" do campo de refugiados de Dadaab, mas não conseguem porque os jovens somalis, muitas vezes, são os proprietários (AGIER, 2002, p. 336, tradução nossa). De acordo com a funcionária das Nações Unidas Silja Ostermann, ${ }^{3}$ a escola é um importante exemplo dessa interação. Nas escolas eles aprendem a conviver com diferentes culturas, religiões, formas de se vestir e de pensar o mundo.

O jornalista Alex Fisberg ${ }^{4}$ ressalta que o contexto de interações entre os funcionários de organizações humanitárias e os refugiados, torna-se difícil pelas muitas atribuições desses funcionários. Poucos funcionários para tantas necessidades. No campo de refugiados, cada agência humanitária tem a sua própria "agenda", ou seja, "sua linha de pensamento ou premissas". 5 A insegurança no campo é outro fator que dificulta o convívio mais intenso. As instalações das organizações estão sempre cercadas por muros altos e vigilância. Quando saem para o trabalho no campo, vão sempre escoltados por oficiais da polícia, ou por uma escolta contratada. Isso desenvolve um distanciamento significativo entre eles. A psicóloga brasileira Deborah Duarte Franco ${ }^{6}$ trabalhou em Dadaab na organização internacional dos Médicos sem Fronteiras, que tem como política institucional, o desenvolvimento de uma maior proximidade com as pessoas que estão ajudando. A sede da organização em Dadaab está localizada no próprio campo, na extensão de Dagahaley, ao contrário das Nações Unidas e de outras organizações humanitárias que estão instaladas no vilarejo de Dadaab. A psicóloga observou que os funcionários saem sem escolta para não criar um distanciamento e constrangimento para os refugiados, que já se encontram em uma situação de extrema vulnerabilidade. Para as pessoas que fugiram de conflitos, estar na presença de armas é sempre muito difícil. Normalmente, as escoltas acompanham os funcionários e visitantes durante todo o seu trajeto nas extensões do campo.

Um jornal e uma revista produzidos pelos refugiados, com auxílio da organização internacional FilmAid, descrevem o dia a dia do campo, compartilham reflexões sobre as

\footnotetext{
${ }^{3}$ Silja é alemã e trabalha nas instalações das Nações Unidas no campo de refugiados de Dadaab. As informações foram obtidas através de entrevista realizada pelo Skype, em 25 de agosto de 2015.

${ }^{4}$ Jornalista brasileiro que esteve em Dadaab em 2011. Entrevista realizada pelo Skype, em 11 de setembro de 2015.

${ }^{5}$ Palavras de Alex Fisberg.

${ }^{6}$ Deborah trabalhou nessa organização em Dadaab, em 2011. Entrevista realizada pelo Skype em 05 de maio de 2015.
} 
conquistas, os desafios e o modo de vida das diferentes culturas e das nacionalidades que fazem parte desse campo de refugiados. Uma nova forma de pensar e de comportamento é desenvolvida. Questões sobre violência doméstica e sexual, mutilação genital feminina, a importância da educação, o combate ao casamento infantil, valorização da mulher, os perigos do uso do $\mathrm{Khat}^{7}$ e a forma de tratamento das pessoas que têm deficiências mentais são exemplos dos temas trabalhados pelas organizações internacionais. Deborah Franco observou que a maior dificuldade do seu trabalho em Dadaab era fazer com que os refugiados entendessem o que é o trabalho de um psicólogo. Muitos são de áreas rurais e não conheciam esse profissional. Havia uma certa resistência na compreensão da necessidade desse tipo de tratamento. Muitos traumas são formados durante a fuga e no período em que passaram em regiões de conflito ou de perseguição. Quando essa resistência era quebrada, ela conseguia interagir e realizar o seu trabalho. Para ela dois pontos eram fundamentais no seu trabalho no campo: o atendimento às mulheres que sofreram violência sexual e o tratamento com correntes, que é atribuído às pessoas com deficiência mental. Em relação a isso, é realizado um trabalho de assistência médica e de conscientização na adoção de outras formas de tratamento para essas pessoas, com o abandono do uso das correntes. ${ }^{8} \mathrm{O}$ empoderamento e o respeito às mulheres é muito desenvolvido no campo de refugiados de Dadaab, onde a violência sexual tem índices preocupantes.

Como mencionado anteriormente, o convívio entre culturas e nacionalidades tão diferentes, também gera conflitos. Entre os refugiados em Dadaab, eles ocorrem, principalmente, por motivos de religião, questões étnicas ou relacionadas à homofobia (HUMAN RIGHTS WATCH, 2002). Os somalis são muçulmanos, em contraste com a religião cristã de refugiados sudaneses e etíopes, por exemplo. As roupas e a religiosidade diferentes dos refugiados que não são muçulmanos são vistos como motivo para agressão verbal ou física. O casamento entre distintas nacionalidades ou até mesmo entre clãs diferentes estimula a perseguição. Muitos casais têm que ser transferidos para outros campos, reassentados em outros países ou protegidos em áreas isoladas do campo pelas organizações internacionais. Mas, apesar das dificuldades e dos conflitos esses casamentos interétnicos não

\footnotetext{
${ }^{7}$ Planta que tem como origem a região queniana do povo Meru e possui efeitos alucinógenos. Seu uso é histórico na África Oriental, porém nos últimos anos tem sido combatido por causa da dependência química que desenvolve.

${ }^{8}$ Esse trabalho psicológico com pessoas com deficiência mental e de uso de khat, desenvolvido pela organização dos Médicos sem Fronteiras em Dadaab, pode ser visto em um pequeno documentário da organização. Disponível em: <https://www.youtube.com/watch?v=SeUIi3iSfBE >. Acesso em: 05 jan. 2016. 
deixam de acontecer. Como Bhabha bem ressalta, é o "inter" "o fio cortante da tradução e da negociação, o entre-lugar" (1998, p. 69).

Alex Fisberg descreveu sua experiência no campo, ao caminhar pelas ruas de Dadaab. O jornalista ressalta o olhar desconfiado dos adultos, ainda muito assustados com a experiência traumática da fuga e com a estranheza do lugar novo. Com as crianças, no primeiro momento, houve um recuo, provavelmente por causa da situação também nova. Um passo à frente, um pouco lento, olhos curiosos, e os gestos de quem está conhecendo algo diferente. Aos poucos foram tocando na pele de cor diferente do jornalista, percebendo os pelos dos braços, estranho para eles, e de repente, sorrisos. O primeiro embate passou, agora seguem algumas brincadeiras rápidas. ${ }^{9} \mathrm{O}$ campo de refugiados de Dadaab é assim formado, entre contradições, ambiguidades, controle, resistências, embates e encontros. Uma complexa dinâmica territorial e de vida, que ainda tem muito para questionar e movimentar.

\section{POR UMA GEOGRAFIA DE ENCONTROS...}

A sociedade do futuro e a do presente vão ser de permanente intercâmbio. E temos que nos acostumar a uma situação em que cada um de nós tem que negociar sua própria identidade, porque dentro de cada um de nós irão conviver diferentes identidades de povos distintos. (Esteban Velasquez, 2015, tradução nossa). ${ }^{10}$

Como uma reflexão final, nessa longa jornada por Dadaab, surgiu a Geografia de encontros, constituída aos poucos, durante o processo de organização da pesquisa de campo e o arrebatamento ao conhecer uma parte do continente africano. Seus povos, costumes, paisagens. Tudo muito diferente, e ao mesmo tempo tão parecido com o Brasil. A questão da alteridade, um dos fatores responsáveis pela contenção dos refugiados nos campos, também foi vivenciada durante a pesquisa. Mais propriamente no Brasil, do que na África. Isso fez com que essa questão surgisse e fosse percebida.

A pesquisa de campo foi importante também, para que se percebesse como fatores gerais, aparentemente distantes dos campos de refugiados, influenciavam em sua formação.

\footnotetext{
${ }^{9}$ Depoimento de Alex Fisberg em entrevista citada anteriormente.

${ }^{10}$ Pensamento exposto pelo Padre Esteban Velazquez da paróquia de Tânger em Marrocos, no documentário Crónicas de um mundo en conflicto: migrantes. Disponível em: $<\mathrm{https} / / \mathrm{www}$.youtube.com/watch? $\mathrm{v}=\mathrm{Kaw} 3 \mathrm{~h} 6$ 2KYUA>. Acesso: 09 out. 2015. O trabalho humanitário do padre Esteban com refugiados e imigrantes em Marrocos e a convivência, muitas vezes solidária e de intercâmbio cultural, entre os moradores e os diferentes migrantes em Tânger, que sobrevivem em campos improvisados construídos por eles nas regiões mais altas, fez com que Esteban Velazquez, influenciado pelos pensamentos do sociólogo espanhol Manuel Castells, refletisse sobre a importância do processo de integração social. 
Os refugiados estão no campo, esquecidos, porque um discurso nocivo sobre as diferenças e sua segregação é criado. Os campos de refugiados podem ser assim compreendidos, como "fábricas de diferenças" abordadas por Achille Mbembe (2013, p. 51). Em Nairóbi ou em outros processos da pesquisa, os principais argumentos ouvidos para a sua contenção foram: eles são possíveis contatos de terroristas do grupo Al Shabaab, são rudes (quando se referiam aos somalis) ou adversários no mercado de trabalho queniano. As diferenças são usadas como argumentos para a formação desses espaços. Michel Agier, ao refletir sobre os campos de refugiados acrescenta que "a 'radicalidade' de sua estranheza aos olhos dos outros não vem de sua nacionalidade ou de sua identidade étnica, mas antes da não cidadania de sua condição", ou seja, "uma alteridade biopolítica" para uma população mantida em uma realidade jurídica à parte das soberanias territoriais então estabelecidas (2015, p. 127, grifo do autor). Ao destacar a imposição dessa alteridade radical, expressa pela construção de muros e cercas, por exemplo, o autor questiona ainda que, a diferença cultural existente nos "campos" ou em outros lugares de contenção de refugiados, nem mesmo é colocada à prova.

A homogeneização imposta desde os processos de colonização europeia e seu vasto alcance, ganhou nova velocidade a partir da década de 1990, quando a tendência que ia em direção ao multiculturalismo ou pluralismo encontrou os impasses dos processos do neoliberalismo, de uma reestruturação na produção e da formação de um discurso relacionado à questão da identidade e da segurança nacional (CASTLES, 2010). A integração social dos imigrantes e refugiados tem se tornado cada vez mais difícil, desde então. Mas, cabe ressaltar a seguinte indagação: A integração social é a solução para o problema dos refugiados no mundo, ou dos campos? Não. Ela diminui o sofrimento, mas não resolve a questão, que está relacionada à prevenção e à resolução de conflitos, embora nos últimos anos esse cenário tenha se tornado cada vez mais complexo, com a influência, também, de fatores ambientais e da instalação de grandes obras de infraestrutura para o desenvolvimento econômico ou urbano. A solução é política, e engloba a reorganização da sociedade e de sua mentalidade capitalista, tão individualista e cheia de muros. Por isso a importância dos encontros.

O filósofo e cientista político camaronês Achille Mbembe reflete sobre as distâncias imaginárias entre os povos e o direito que todas as pessoas têm de viver dignamente nesse mundo, que é por definição, único. O autor observa que:

Por mais que insistamos em criar fronteiras, erguer muros, diques e cercas, dividir, selecionar, classificar e hierarquizar, tentar excluir da humanidade aqueles e aquelas que desprezamos, que não se parecem conosco ou com quem pensamos não ter nada 
em comum à primeira vista, existe um único mundo apenas, e todos temos direito a ele. Em princípio, ele pertence a todos nós, igualmente; somos todos seus herdeiros, por mais que nossas maneiras de habitá-lo variem. Daí, justamente, a pluralidade de formas culturais, linguagens e modos de vida que existem. Dizer isso não equivale, absolutamente, a ocultar a violência que ainda caracteriza o encontro de povos e de nações. Trata-se apenas de lembrar um dado imediato, um processo inexorável a cujas origens exatas, no fundo, é difícil remontar: a forma irreversível como culturas, seres e coisas se emaranham e entrelaçam. Esse entrelaçamento, que começou no passado e prossegue hoje, continuará, no futuro, a tornar nossa existência ao mesmo tempo incerta e repleta de promessas (MBEMBE, 2013, p. 45).

A artista Marie Ange Bordas e suas importantes e sensíveis reflexões sobre os deslocamentos humanos forçados lembra que "a dignidade de cada pessoa baseia-se, entre outras tantas coisas, no fato de que só ela vê o mundo como ela o vê, só ela guarda em seu olhar e em sua voz uma história única. Por isso é preciso encontrar o outro, ouvir o outro, ser também outro" (BORDAS, 2006, p. 05).

A diversidade existente no meio natural é aceita como norma, mas a humana tenta-se moldar em um invólucro chamado "sociedade", com um rigor na homogeneidade. É necessário ir além da homogeneização, numa tentativa de "descolonizar nossas mentes".11 Seguindo as palavras de Paul Claval:

A experiência do espaço é, pois, fundamentalmente, a de suas interrupções, suas rupturas, seus contrastes, sua heterogeneidade. Esta não resulta somente da multiplicidade das condições naturais ou da diversificação das atividades produtivas. Ela nasce da experiência que os homens têm dos lugares e das emoções que esta suscita (CLAVAL, 2010, p. 55).

A geografia como ciência do mundo, dos seus lugares e povos, precisa desses encontros. Não só o espaço, não só as pessoas. Ver o espaço "através" das pessoas, uma relação, algo além do uso e do vivido. Um transpassar de espaço/pessoas que gera conhecimento transforma-se em geografia. Compreender o todo é compreender melhor o

\footnotetext{
${ }^{11}$ Reflexão exposta pelo ecologista e ativista queniano Gathuru Mburu em seu artigo intitulado Decolonizing our minds and our lands: reviving seeds, culture, and african strenght, editado por Beverly Bell e Simone Adler para o jornal Daily Kos em 16 de dezembro de 2015. Gathuru Mburu tem desenvolvido projetos agrícolas no Quênia que buscam reviver o conhecimento dos povos ancestrais e sua relação harmônica com a Natureza, reafirmando a sua importância e valor, frente às práticas coloniais de exploração, que segundo o autor, ainda persistem na África. Seu importante projeto tem alcançado importantes avanços no Quênia, assim como criado uma rede de solidariedade entre outros países africanos que têm adotado, ou revivido, também essas práticas agrícolas. Disponível em: <https://www.dailykos.com/stories/2015/12/16/1460730/-Decolonizing-Our-Minds-and-OurLands-Reviving-Seeds-Culture-and-African-Strength>. Acesso em: 16 dez. 2015. 
singular. Só conhecendo o mundo como ele é, com suas diversas potencialidades e possibilidades é que se sai das sombras desse desconhecer para a luz dos encontros.

\section{CONSIDERAÇÕES FINAIS}

Os vinte seis anos de existência do campo de refugiados de Dadaab e o seu constante fluxo de refugiados, permitem, apenas, traçar algumas considerações finais sobre determinadas faces de sua complexidade. Dadaab é um fenômeno em desenvolvimento ${ }^{12}$ e a importância de seu estudo vai além das feições relacionadas ao controle ou à biopolítica que esclarecem questões centrais da organização da vida em sociedade, como um "pequeno observatório do mundo" (AGIER, 2015, p. 119). Nesse "rascunho de cidade" (AGIER, 2011, p. 125) moldado por diversas nacionalidades, o movimento de "ir e vir" (BHABHA, 1998, p. 22) articula as diferenças culturais e cria novas formas de organização em coletividade.

Na contemporaneidade, ao "mesmo tempo que a modernidade se transforma e se torna cada vez mais um regime global e híbrido", observa-se "uma condição cosmopolita banal" característica desses espaços de fronteira com lugares, tempos e "identidades incertas, ambíguas, incompletas, opcionais" em "situações indeterminadas" ou "de entre dois" (AGIER, 2015, p. 28), como em Dadaab e suas novas formas de lidar com as diferenças, tão discutidas nos últimos anos. Esse cosmopolitismo do campo de refugiados de Dadaab possui os aspectos abordados pelo historiador queniano Godwin Rapando Murunga (2012), ${ }^{13}$ ao observar a tradição histórica cosmopolita de Nairóbi com origem no período colonial, desenvolvida pela necessidade dos diferentes povos que ali viviam (africanos, asiáticos e europeus) de transcender às diferenças, criando uma solidariedade contra os processos de segregação colonial. Até hoje Nairóbi é visivelmente marcada por esse cosmopolitismo. Cada recanto dessa cidade revela uma intensa pluralidade de culturas. Nesse sentido, é importante reiterar que "se o campo de refugiados é bem a forma endurecida de uma 'fronteira' espacial e temporal entre cidadanias e localidades perdidas e ainda não reencontradas, ele é também a prova de um pequeno mundo cosmopolita" (AGIER, 2015, p. 128, grifo do autor). A importância da convivência entre diferentes culturas e as oportunidades que isso pode criar, percebidos nos aspectos cosmopolitas de Nairóbi e agora referente ao contexto dos campos de

\footnotetext{
${ }^{12}$ É importante destacar, nesse aspecto, a existência de alguns campos de refugiados palestinos que estão funcionando desde a década de 1950.

${ }^{13}$ As reflexões do autor sobre essa concepção de cosmopolitismo têm origem nos pensamentos de Ulf Hannerz (1990), Kwame A. Appiah (2006) e Craig Calhoun (2003). 
refugiados, são destacadas, por exemplo, na criação em 2016, do campo de refugiados Kalobeyei próximo ao lago Turkana (Noroeste do Quênia). Instituído como um projeto experimental das Nações Unidas em parceria com o governo queniano, Kalobeyei possui uma política de assentamento e de comunidade integrada, como tem sido adotada em Uganda, ao invés da formação de “campos”. Nesse projeto a integração social é estimulada, assim como a coexistência entre os refugiados e a comunidade local, com o desenvolvimento de atividades agrícolas sustentáveis, reaproveitamento de água, geração de empregos e de comércio e um desenvolvimento urbano planejado. As possibilidades geradas através da coexistência é o coração do projeto.

Esse espaço fronteiriço, tanto em sua localização quanto em sua essência, revela uma "vida no limite" (HAESBART, 2014, p. 274) repleta de proibições e cerceamentos, da mobilidade ao desenvolvimento de uma infraestrutura urbana. No entanto, esses limites do campo de refugiados de Dadaab, além de serem contornados, em relação às práticas de contenção territorial, são transpassados, mostrando que os conflitos ou estranhamentos vivenciados nesse espaço então delimitado, dinamizam o desenvolvimento de "realidades distintas", plurais (HAESBART, 2014, p. 274), pois “o limite não é onde uma coisa termina, mas como os gregos reconheceram, de onde alguma coisa dá início à sua essência" (HEIDEGGER, 1954, p. 06). A vulnerabilidade dos refugiados nesse território dá lugar, com o tempo, a uma resistência negociada em relação às imposições normativas e à convivência, criando nessa descontinuidade espacial e de sentidos outros ritmos, outras geografias...

\section{REFERÊNCIAS}

AGIER, Michel. Between War and City: Towards an Urban Anthropology of Refugee Camps. Journal of Contemporary Ethnography. Londres, v. 3, n. 3, p. 317-341, set. 2002. Antropologia da Cidade: lugares, situações, movimentos. São Paulo: Terceiro Nome, 2011.

. Migrações, descentramento e cosmopolitismo: uma antropologia das fronteiras. Trad. Bruno César Cavalcanti, Maria Stela Torres B. Lameira, Rachel Rocha de A. Barros. São Paulo: UNESP; Alagoas: Edufal, 2015.

BARBOSA, Muryatan Santana. Homi Bhabha leitor de Frantz Fanon: acerca da prerrogativa pós-colonial. Revista Crítica Histórica. Maceió, n. 5, p. 217-231, jul. 2012. 
BHABHA, Homi K. O local da cultura. Trad. Myriam Ávila, Eliana Lourenço de Lima Reis, Gláucia Renate Gonçalves. Belo Horizonte: UFMG, 1998.

BORDAS, Marie Ange. Deslocamentos: uma proposta de integração por meio da arte. Revista Imaginário. São Paulo, v. 12, n. 13, 2006.

BRAGA, Jorge Luiz Raposo. Os campos de refugiados: um exemplo de "espaços de exceção" na política contemporânea. In: $3^{\circ}$ ENCONTRO NACIONAL ABRI 2011. Proceedings online... São Paulo: Associação Brasileira de Relações Internacionais, Instituto de Relações Internacionais - USP, 2011.

CASTLES, Stephen. Entendendo a migração global: uma perspectiva desde a transformação social. REMHU-Revista Interdisciplinar da Mobilidade Humana. Brasília, v. 18, n. 35, p. 11-43, jul./dez. 2010.

CLAVAL, Paul. Terra dos Homens: a geografia. Trad. Domitila Madureira. São Paulo: Contexto, 2010.

GOETTERT, Jones D.; MONDARDO, Marcos L. O "Brasil Migrante": Gentes, Lugares e Transterritorialidades. GEOgraphia. Rio de Janeiro, v. 11, n. 21, p. 101-136, 2009.

GRBAC, Peter. Civitas, polis, and urbs: Reimagining the refugee camp as the city. Refugee Studies Centre. Oxford, n. 96, 2013.

HAESBAERT, Rogério. Viver no Limite: território e multi/transterritorialidade em tempos de in-segurança e contenção. Rio de Janeiro: Bertrand Brasil, 2014.

HALL, Stuart. Quem precisa da identidade? In: SILVA, Tomaz Tadeu da; HALL, Stuart; WOODWARD, Kathryn (Orgs.). Identidade e diferença: a perspectiva dos estudos culturais. Petrópolis: Vozes, 2000. p. 103-133.

HEIDEGGER, Martin. Bauen, Wohnen, Denken. In: Vorträge und Aufsätze. Pfullingen: G. Neske, 1954. Tradução de Marcia Sá Cavalcante Schuback, disponível em: <http://www. prourb.fau.ufrj.br/jkos/p2/heidegger_construir,\%20habitar,\%20pensarpdf $>$. Acesso em: 25 jul. 2017.

HUMAN RIGHTS WATCH. Hidden in plain view: refugees living without protection in Nairobi and Kampala. 2002. Disponível em: <https://www.hrw.org/reports/2002/kemyugan /kenyugan.pdf $>$. Acesso em: 20 mai. 2016.

MBEMBE, Achille. Existe um único mundo apenas. In: BORDAS, Marie Ange (Org.). Geografias em Movimento. São Paulo: Edições Sesc, n. 9, 2013, p. 43-65.

MINCA, Claudio. Geographies of the camp. Political Geography. Wageningen, v. 49, p. 74$83,2015$. 
MURUNGA, Godwin Rapando. The cosmopolitan tradition and fissures in segregationist town planning in Nairobi, 1915-23. Journal of Eastern African Studies. Londres, v. 6, n. 3, p. 463-486, 2012.

UNHCR/KENYA - United Nations High Commissioner for Refugees/Kenya. UNHCR Dadaab - Kenya: population statistics. 2017. Disponível em: <http://reliefweb.int/sites/relief web.int/files/resources/REG_H04CampPopulationbyCoOSexAgeGroup\%28Final\%29January 2017.pdf>. Acesso em: 20 mar. 2016.

VIDAL, Laurent; MUSSET, Alain; VIDAL, Dominique. Sociedades, mobilidades, deslocamentos: os territórios da espera. $\mathrm{O}$ caso dos mundos americanos (de ontem a hoje). Confins. São Paulo, n. 13, 2011, p. 1-24.

WEITZBERG, Keren. We Do Not Have Borders: Greater Somalia and the predicaments of belonging in Kenya (1870-2015). Athens: Ohio University, 2017. [No prelo]. 